\title{
A study on parent child relationship as perceived by adolescent boys
}

Sunita Chouhan and Jayshree Godara

Received: 11.10.2017; Revised: 07.04.2018; Accepted: 26.04.2018

See end of the paper for authors' affiliations

Sunita Chouhan

Department of Human

Development and Family Study,

College of Home Science, S.K.

Rajasthan Agriculture University,

Bikaner (Rajasthan) India

Email : sunita.singh55@gmail.

com
ABSTRACT : Adolescence is the period of transition between childhood to adulthood. It is a period when rapid physiological changes and demands for new social roles take place. The period of adolescence not only brings physical changes but psychological changes that make a child qualitatively different person. These changes affect the personality and adjustment in later life. It is widely assumed that conflict between parents and children is an inherent feature of family life in adolescence, but systematic research on the so called generation gap indicates that the phenomenon has been exaggerated in the popular media. Early adolescence may be a time of the heightened bickering and somewhat diminished closeness in the parent-child relationship, but most disagreement between parent and young teenagers are over fairly mundane maters and most teenagers and parent agree on the essentials. Therefore, the present study was undertaken to assess the parent-child relationships as perceived by Adolescent boys of Government Senior Secondary Schools of Bikaner City (Rajasthan). The total sample for the present study consisted of randomly selected 90 boys from three randomly selected Government Senior Secondary Schools. Data were collected through a standardized tool i.e. Parent-Child Relationship scale developed by Rao (2001). Frequency, percentage, was computed, respectively to assess each of ten dimensions of parent-child relationship of boys (12-18 years). The result revealed that most of the boys perceived their parent-child relationship under sometimes level regarding selected dimensions of parent-child relationship. Thus it can be concluded that adolescents under study felt that their parents attitude and behaviour towards them was mediocre, i.e. their parents were neither too much protecting, loving etc. not too much neglecting, rejecting, demanding etc.

KEY WORDS: Adolscent boys, Parent child, Physical changes, Teenagers

- HOW TO CITE THIS PAPER : Chouhan, Sunita and Godara, Jayshree (2018). A study on parent child relationship as perceived by adolescent boys. Asian J. Home Sci., 13 (1) : 247-249, DOI: 10.15740/HAS/ AJHS/13.1/247-249. Copyright@ 2018: Hind Agri-Horticultural Society. 